\title{
Cadernos
}

e-ISSN: 2525-3514

DOI: $10.5585 /$ cpg.v17n2.10315

\section{OS SABERES E FAZERES DAS CRIANÇAS QUILOMBOLAS MARAJOARA-SAlvaterra-PARÁ}

\author{
THE KNOWLEDGES AND PRACTICES OF QUILOMBOLA MARAJOARA \\ CHILdRen - SAlvaterra - Pará
}

\begin{abstract}
Erica de Sousa Peres
Mestre em Educação pela Universidade do Estado do Pará. Docente da Secretaria de Educação do Pará. Pará - PA - Brasil ericaperes_22@yahoo.com.br

Nazaré Cristina Carvalho Doutora em Educação Física pela Universidade Gama Filho. Professora Adjunta da Universidade do Estado do Pará. Pará - PA - Brasil n_cris@uol.com.br
\end{abstract}

\begin{abstract}
Resumo: O texto apresenta uma análise dos saberes e fazeres de crianças quilombolas marajoaras da Vila de Mangueira, "o quilombo-mãe”, considerado um importante território negro na Amazônia Marajoara. Assim, tivemos como navegantes quinze crianças que conduziram o "mergulho" nos saberes da cultura quilombola a partir do seu brincar e de suas vivências. Estabeleceu-se um diálogo com a "Pedagogia da Atenção", que possibilitou desvelar saberes e processos educativos peculiares que permeiam a infância negra da Amazônia, em seguida, destacou-se a importância de ouvir as narrativas de meninos e meninas com o objetivo de compreender os seus modos de aprender os saberes advindos de suas vivências. Práticas essas que se manifestam espontaneamente na vida cotidiana, por meio de interações. Diante disso, percebemos a inserção de crianças na dinamicidade e na complexidade do contexto social da comunidade remanescente de quilombo, bem como as suas atuações no trabalho de preservação das tradições da comunidade.
\end{abstract}

Cadernos de Pós-graduação, São Paulo, v. 17, n. 2, p. 99-119, jul./dez. 2018. 
Palavras-chave: Crianças Quilombolas. Saberes. Educação.

\begin{abstract}
The text presents an analysis of the knowledges and practices of quilombola Marajoara children from the village of Mangueira, "the mother quilombo", considered an important black territory in the marajoara amazon. Thus, we had as navigators fifteen children who led the "diving" into the knowledge of the quilombola culture starting from their play and their experiences. A dialogue was established with the "Pedagogy of Attention", which made it possible to uncover the peculiar educational processes that permeate the black childhood of amazon, then, there was emphasized the importance of listening to the narratives of boys and girls in order to understand their ways of learning the knowledge that comes from their experiences. Practices that manifest themselves spontaneously in daily life, through interactions. In view of this, we noticed the insertion of children in the dynamicity and complexity of the social context of the remaining community of quilombo, as well as their actions in the work of preserving the traditions of the community.
\end{abstract}

Keywords: Quilombola children. Knowledges. Education.

\title{
Introdução
}

presente artigo baseia-se na pesquisa de mestrado realizada no Pro-
grama de Pós-Graduação em Educação, da Universidade Estadual do Pará (UEPA), no período de 2016-2018. Com a pesquisa buscamos analisar os saberes da cultura quilombola marajoara a partir do brincar de crianças e de suas vivências, uma vez que as consideramos produtoras de uma cultura que influencia e é influenciada pelo contexto em que vivem. Em vista disso, consideramos essas crianças como sujeitos "produtores de cultura", ou seja, protagonistas de sua própria história, como bem reitera Conh (2005, p. 35):

As crianças não são apenas produzidas pelas culturas, mas também produtoras de cultura. Elas elaboram sentidos para o mundo e suas experiências compartilhando plenamente de uma cultura. Esses sentidos têm uma particularidade, e não se confundem e nem podem ser reduzidos àqueles elaborados pelos adultos. 
Nessa perspectiva, são crianças que compartilham experiências e vivências entre si e com os adultos, criam sentidos e significações particulares para os momentos vividos, assim como produzem representações simbólicas para suas brincadeiras e para seu o convívio, isto é, para o seu cotidiano. Por essa mesma lógica, Quinteiro (2009) destaca que a criança é um ser social que constitui mediações simbólicas, quer sejam pelos gestos, pelas brincadeiras, pelo faz-de-conta, quer seja pela linguagem em suas diversas manifestações, e tais mediações, por sua vez, são constitutivas do próprio ser humano.

Em conformidade com essa postura, as crianças quilombolas marajoaras são capazes de constituir suas "mediações simbólicas", e, assim, apresentam o mundo e a si mesmas. A partir do brincar que se constroem na coletividade, e dessa maneira, elas ressignificam o universo em que em vivem, isto é, demonstraram como a vivência lúdica integra o cotidiano da Vila de Mangueira, pois propicia uma reflexão sobre a realidade delas. Conforme a disposição das árvores, jogam seu futebol, utilizam elementos da natureza como brinquedo e/ou parte das brincadeiras, fazem da maré um local propício e divertido para as brincadeiras.

Notamos que a ludicidade se faz presente nas vivências cotidianas das crianças quilombolas marajoaras, como fantasia, imaginação e sonhos que se constroem como um labirinto de teias urdidas, com materiais simbólicos que são próprios da infância quilombola. No entendimento de Santin (2002, p.16) a ludicidade é uma "tessitura simbólica fecundada, gestada e gerada pela criatividade simbolizadora da imaginação de cada um".

Podemos dizer que a chamada "tessitura simbólica" expressa no lúdico se revela no cotidiano das crianças quilombolas marajoaras principalmente, quando elas ocupam esse território étnico com suas brincadeiras, suas capacidades de criar, imaginar e sonhar, propiciando práticas educativas que se materializam em diversos saberes. 


\section{$1 \mathrm{Um}$ breve contexto da comunidade remanescente de quilombo Vila de Man- gueira-Salvaterra-Marajó-Pará}

A comunidade remanescente de quilombo Vila de Mangueira localiza-se na mesorregião da ilha do Marajó. De acordo com dados do IBGE possui 442 moradores e representa 17\% da população do município de Salvaterra. A formação histórica dessa comunidade, conforme relatos orais, deu-se com a chegada dos negros escravizados que vinham fugidos das fazendas de Soure e nesse território encontraram abrigo, povoando e formando famílias que, posteriormente, foram se espalhando pela região, dando origem a outras comunidades remanescentes de quilombos.

Segundo as informações colhidas em estudos relacionados a quilombos marajoaras, e também com pessoas pertencentes às comunidades do entorno de Mangueira, o mito de origem das comunidades remanescentes de quilombo de Salvaterra está sempre ligado a alguém que veio da Vila de Mangueira e que se instalou em outra terra formando outro quilombo. Assim, esta figura atua como o elo entre todos os outros quilombos, sendo denominada de "quilombo-mãe"

1 , isto é, aquele que gerou todos os outros.

A comunidade remanescente de quilombo Vila de Mangueira pode ser considerado o primeiro quilombo do município de Salvaterra, dado que é ressaltado pela oralidade e pela memória. Dessa forma, essa comunidade se estabelece enquanto mito de origem preservado na memória dos quilombolas. Essa informação vem ao encontro do pensamento de Le Goff (1992) ao afirmar que a memória é a propriedade onde se conserva certas informações. Percebe-se que é a partir desta propriedade que as informações sobre a origem ou a história do lugar são transmitidas de geração em geração.

Por sua vez, a comunidade remanescente de quilombo Vila de Mangueira possui seu território certificado junto ao órgão responsável (Fundação Cultural Palmares). 
De acordo com este órgão, a abertura do processo de certificação da comunidade ocorreu no ano de 2011. Contudo, a comunidade ainda aguarda o processo de titulação da terra pelo Instituto Nacional de Colonização e Reforma Agrária - INCRA, na vigência do Decreto n. 4.887/2003.

Vale ressaltar que geograficamente, a Vila de Mangueira se subdivide em pequenas comunidades contidas num só "território étnico", que são formadas por lotes de terras que agregam famílias, que inclusive se utilizam de nomes diferenciados, tais como: Mangueira, São João, Salvar, Nascimento, Divindade, Mucajá e Vila Pereira, como se fossem pequenos bairros. Conforme Anjos (2010), território étnico seria o espaço construído, materializado a partir das referências de identidade e pertencimento territorial. Geralmente, sua população tem um traço comum.

Desse modo, esse "território étnico" evidencia a presença negra na Amazônia Marajoara, que resiste ao tempo e se destaca por ser considerada a primeira e a maior comunidade quilombola do município. Mediante a este contexto, problematizar os saberes do brincar a partir das vivências de crianças quilombolas do Marajó perpassa por uma concepção de que os saberes culturais são construídos e ressignificados pelos próprios sujeitos em seu cotidiano.

Assim, as crianças podem ser vistas como sujeitos que ressignificam sua vivência e trazem e/ou constroem saberes, haja vista que estão envolvidas num território onde educação e a cultura se entrelaçam, situação que não pode ser desconsiderada pelo contexto educacional. Diante disso, nossa pesquisa visa contribuir para que as crianças sejam sujeitos ativos e autônomos de sua história, tendo em vista que, quando se propõe pesquisar a partir da perspectiva da criança, permite-se que está se desvele a partir do seu brincar, já que o lúdico é algo vital e primordial para o desenvolvimento infantil.

Posto isso, pretendeu-se colaborar com o conhecimento em torno de uma história que foi silenciada pela história oficial, que é a história do povo negro que aportou 
na Amazônia Marajoara, e assim conferir um direito à voz daqueles que ficaram à margem, no sentido de desvelar "o que não foi dito", mas ainda assim, constitui socialmente, historicamente e culturalmente “o ser amazônico". Segundo a Fundação Cultural Palmares2, o estado do Pará é o quarto estado com o maior número de comunidades quilombolas. Ademais, a 3Malungu (2006) destaca que o Pará concentra o maior número de comunidades quilombolas já titulados4, sendo um dos estados pioneiros a reconhecer a importância dessas comunidades enquanto povos tradicionais que se caracterizam pelo pertencimento da terra, laços de parentesco e apropriação do território.

Isto evidencia e marca a presença negra nesse recorte amazônico que é o território marajoara, que ainda hoje resiste, luta e é representado pela existência de diversas comunidades quilombolas e inúmeras famílias de afrodescendentes que compõem a população marajoara. Nessa perspectiva, reconhecer e valorizar a contribuição negra para a Amazônia é imergir em um amplo espaço de pesquisa e análise, que ajuda a elucidar as contribuições do povo negro na Amazônia.

Vale destacar que este objeto de pesquisa se ancora na Lei n. 10.639/03, que torna obrigatório o ensino de história e cultura africana e afrodescendente, dentro desse viés, centramos no recorte de desvelar os saberes do brincar de crianças quilombolas marajoaras, considerando que o povo negro contribuiu e contribui significativamente para a história social da Amazônia Marajoara. Assim, ressaltar a voz da criança envolta na etnicidade expressa nos quilombos possibilita que compreendamos através de seu brincar e de suas brincadeiras, importantes aspectos da cultura quilombola marajoara.

O aprendizado com as crianças da Vila de Mangueira, permitiu-nos compreender que elas precisam ser ouvidas, pois, ainda que pequenas, contam com muitas experiências, é nesse sentido que suas vozes devem ser consideradas como um dado relevante, pois compreendem e analisam de forma significativa as vivências cotidianas do contexto em que vivem. 


\section{A Travessia Metodológica e o Diálogo com as crianças}

A travessia metodológica corresponde aos caminhos que delineamos para compreender os saberes presentes nas vivências lúdicas das crianças quilombolas marajoaras, tendo como eixo central o olhar da própria criança. Para isso, fez-se necessário aguçarmos a sensibilidade para alcançar a sapiência e a perspicácia das crianças e assim também nos abrirmos para o aprendizado com elas e junto delas.

Nesse sentido, foi preciso compreender os diferentes elementos e/ou situações que se apresentam no decorrer da pesquisa, já que o trabalho com as vozes de crianças, na acepção de Cruz (2008, p. 13) significa "buscar formas de ouvir as crianças, explorando as múltiplas linguagens, tem como pressupostos a crença de que elas têm o que dizer e o desejo de conhecer o ponto de vista delas" Baseados nesse "desejo de conhecer o ponto de vista delas", foi imprescindível a escolha teórica, epistemológica e metodológica que propiciou compreender e analisar o universo infantil em seus próprios termos, em outras palavras, em seus espaços de vivência.

Centrados nessa perspectiva, buscamos compreender a infância a partir da percepção de uma sociologia da infância, para isso estabeleceu-se um diálogo com os seguintes autores: Corsaro (2011), Alves (2014), Quinteiro (2009) e Conh (2005). No âmbito da cultura e ludicidade, enveredamos pelos estudos de Geertz (2012), Thompson (1995), Santin (2002), Huizinga (2012), Caillois (1990) e Brougére (2000). E no processo de análise dos dados buscamos aproximação bibliográfica com a "Pedagogia da Atenção”, partindo de Brandão (2002), Martinic (1994) e Tim Ingold (2010), nomes fundamentais para a compreensão os modos de saber e fazer, e, nesse caso, auxiliando-nos a compreender o universo lúdico das crianças da Vila de Mangueira. 
Como o estudo considera as crianças quilombolas como sujeitos ativos da pesquisa, em um primeiro momento, propusemos um exercício de ouvir as suas narrativas, ao mesmo tempo em que a observação de suas vivências lúdicas foi considerada essencial para a coleta de dados. A observação participante foi de suma importância, pois o tempo que estivemos com elas propiciou o envolvimento e confiança delas no sentido de permitir que vivenciássemos o seu cotidiano, partilhando de suas experiências. Nesse sentido, vale ressaltar que a pesquisa com crianças é instigante e inspiradora, pois elas têm muito a dizer e a ensinar, sobretudo no que tange seu próprio bem viver e de sua comunidade, precisamos escutá-las com mais frequência em nossas pesquisas para assim reverenciar a leveza de quem tem no lúdico a sua essência.

Vale ressaltar que como se trata de uma pesquisa com crianças, os aspectos éticos foram mantidos, de acordo com a Resolução n.196/96 da Organização Mundial da Saúde - OMS, resguardando os nomes dos sujeitos envolvidos, além da solicitação de assinatura do TCLE pelas crianças e seus responsáveis. Diante disso, a pesquisa foi encaminhada ao Comitê de Ética, e tendo sido aprovada.

\section{O cotidiano lúdico das crianças quilombolas marajoaras}

O brincar nas vozes das crianças assume uma função significativa em suas vidas, demonstram que suas infâncias são marcadas como tempo de brincar. Nesse sentido, quando indagadas sobre o que é brincar, responderam:

Brincar para mim é legal, é divertido, é ser livre, é poder sair para correr (Kelé, 10 anos).

Ficamo muito alegre nas brincadeiras, a gente ri, é muito bom, bom mermo (Sarubé, 10 anos).

Eu brinco porque é divertido (Tia Coconda, 09 anos).

Gosto de brincar com meus amigos porque é legal (Noca, 09 anos)

Cadernos de Pós-graduação, São Paulo, v. 17, n. 2, p. 99-119, jul./dez. 2018. 
Eu brinco de bola, de um monte de brincadeira legal (Biel, 09 anos).

A gente brinca junto, um vai chamar o outro pra brincar, é muito legal (Cai Cai, 09 anos).

Eu brinco para me divertir, o cara ri muito com as brincadeiras que a gente brinca (Lily, 09 anos).

Brincar é se divertir (Jarubá, 10 anos).

Ah! Brincar é se divertir, é rir, é se distrair, é bom (Catú, 10 anos)!

Percebemos nas falas das crianças que o brincar está relacionado à diversão, ao lazer, ao prazer de estar com os amigos, a jogar futebol, a jogar baralho. Demonstram, assim, que o brincar para elas é uma atividade prazerosa que se realiza na coletividade, isto é, que existente na co-dependência do outro.

Ao ressaltarem a diversão e o lazer como sensações vividas pelo brincar, resgatam o dizer de Caillois (1990) quando considera que imagens e símbolos se envolvem nas manifestações lúdicas, associando simultaneamente alegria e divertimento. Além disso, no que tange ao simbólico, Geertz (2012) e Thompson (1995) convergem suas ideias, considerando a questão simbólica como reveladora das construções culturais presentes nos fenômenos.

Assim, as crianças tornam-se brincantes e ocupam os espaços da comunidade e o seu tempo-infância, realizando brincadeiras de acordo com a sua realidade local. Com essa perspectiva, retoma Brougère (2000), quando ressalta a brincadeira como um processo de relações interindividuais, portanto cultura, já que parte dos elementos que as crianças encontram no seu ambiente imediato, em parte estruturado por seu meio, são usados para se adaptar às suas capacidades. 
Destarte, as manifestações lúdicas das crianças da Vila de Mangueira convergem enquanto práticas culturais, visto que elas em suas falas elaboram um discurso simbólico sobre suas vivências lúdicas, nas quais os significados são atribuídos a partir de suas interpretações culturais. Assim, ao longo da permanência na comunidade, foi possível observar diferentes formas de brincar entre as crianças e elas relataram várias outras possibilidades de diversão.

Também é visível que a liberdade e a espontaneidade se fazem presentes no cotidiano das crianças da Vila de Mangueira, e as brincadeiras perpassam os diversos momentos da vida cotidiana delas. Desse modo, as crianças inventam o seu brincar, decidem as regras dos jogos e ressignificam a natureza conforme a necessidade das brincadeiras, criando brinquedos diversos. Nesse contexto, o brincar e as brincadeiras são aspectos fundamentais para o processo de socialização e vivência da infância singular dos quilombos marajoaras.

\section{Os Saberes e Fazeres do brincar das crianças da Vila de Mangueira-Salvaterra- Marajó-Pará}

Apresentamos aqui uma educação que se contrapõe à hegemonia do saber escolarizado, considerando processos educativos que se articulam com as manifestações lúdicas vivenciadas pelas crianças quilombolas marajoaras em seu cotidiano, situando, assim, este estudo do outro lado da linha abissal.

De acordo com Santos (2007), o pensamento moderno é abissal, pois, no campo do conhecimento, o pensamento abissal consiste na concessão à ciência moderna, do monopólio da distinção entre o verdadeiro e o falso, isto é, à luz da modernidade distingue o conhecimento que deve adentrar a escola e ser legitimado, e aquele que fica às margens, excluído da educação escolar. 
Dito isso, optamos por apresentar aqui uma educação que pretende romper com a tradicional valorização do saber científico presente na escola, e passa a considerar saberes significativos para o cotidiano dos sujeitos, pois se alinham com a realidade e valorizam seus modos de pensar, fazer e viver, e se constituem enquanto práticas educativas para além da escola. Nas falas que se seguem os intérpretes expressam um conjunto de diferentes saberes, porém muito significativos para o seu contexto local.

A cidreira, o boldo, a erva-doce, o capim santo a gente usa pra fazer chá, é bom para dor de cabeça, pra barriga, põe a água pra ferver, borbulha e quando borbulha tira do fogo e põe as folha e abafa, tá pronto, mas a gente bebe quando não tem café também (Catú, 10 anos)!

Eu aprendi a nadar com o Teta. Ele mostra como é, a gente fica olhando, vendo ele fazer, depois ele joga a gente no meio da maré, aí a gente sai nadando (Cai Cai, 09 anos).

A gente fica olhando a madrinha fazer a comida, ela manda olhar bem, ver como faz tudo direitinho, depois, no outro dia, ela manda eu fazer e dar pr'as meninas, porque aí eu já aprendi e posso ensinar pra elas. Eu sei fazer arroz, feijão, cuidar do peixe, fazer mingau de caramujo, gosto de ajudar a madrinha, acho legal (Lelé,12 anos)!

Percebemos nesses depoimentos o trânsito de muitos saberes, conhecimentos sobre as ervas e o modo de prepará-las. Segundo Catú, elas têm duas utilidades: servem tanto para curar algum problema como dor de barriga, quanto para substituir o café. Cai Cai e Lelé demonstram a maneira como aprenderam a nadar e a cozinhar, respectivamente.

As falas das crianças corroboram um processo de aprendizado diferenciado do escolarizado. Trata-se de uma aprendizagem vivenciada na prática, e, como tal, expressam-se exatamente como são aprendidas. As crianças da Vila de Mangueira convivem com o que Medaets (2011, p. 10) denomina de "saberes que não são ditos, informados, 
mas sim vividos, mesmo que através da observação". É através da experiência continuada, em primeiro lugar, como observador ativo.

Como observadores ativos, as crianças quilombolas aprendem "as coisas do mundo" de acordo com o "modo de ensinar" específico do contexto em que vivem. Nessa perspectiva, Brandão (1995) assinala que, conforme o tipo de saber, existe um modo de ensinar. Assim:

Tudo o que é importante para a comunidade, e existe como algum tipo de saber, existe também como algum modo de ensinar. Mesmo onde ainda não criaram a escola, ou nos intervalos dos lugares onde ela existe, cada tipo de grupo humano cria e desenvolve situações, recursos e métodos empregados para ensinar às crianças, aos adolescentes, e também aos jovens e mesmo aos adultos, o saber, a crença e os gestos que os tornarão um dia o modelo de homem ou de mulher que o imaginário de cada sociedade - ou mesmo de cada grupo mais específico, dentro dela - idealiza, projeta e procura realizar (BRAND ̃̃O, 1995, p. 22, grifo do autor).

Assim, elas aprendem o que é importante para a comunidade onde vivem a partir de algum saber e com um modo de ensinar peculiar. $\mathrm{O}$ desenvolvimento e a articulação desses saberes são significativos e relevantes para a práxis e o bem viver dessas crianças. Dito de outra maneira, os saberes que circulam nas vivências das crianças explicitam práticas cotidianas necessárias para a vida e/ou para a sobrevivência. Isso pode ser percebido na voz dos respectivos entrevistados: Tia Coconda, Biel e Catú, ao dialogarem sobre os seus saberes acerca da maré, quando indicavam que devíamos ir naquele momento para o rio:

A gente sabe quando a maré tá viva, é quando encher, aí é muito bom pra brincar, pra nadar. Quando ela tá morta, água morta, é quando seca, o Teta que diz pra gente, ele que ensina, pra nós saber (Tia Coconda, 09 anos). 
Lá na maré não dá pra brincar muito no fundo, ela puxa, eu sei porque eu já vi puxar. Meu tio Teta ensina à gente as coisas do mundo, ensina a gente a se defender da maré quando ela tá malvada (Biel, 09 anos).

Quando vai encher, a gente já sabe, porque a gente já aprendeu a lidar com a maré e aí a gente vai tudinho pra lá porque vai ser bom de brincar, nadar, pescar, ficar de boa (Catú, 10 anos).

Fica vidente nos trechos das falas acima a relação estabelecida com a maré, algo que está para além do brincar, embora este seja um dos lugares preferidos para essa prática. A maré é também o lugar de aprender acervos do cotidiano de uma vila de pescadores. Ademais, o modo de aprender as "coisas do mundo" se conecta com a figura do Seu Teta, que se faz presente em muitos momentos na voz das crianças, principalmente quando se trata da maré, evidenciando que o modo de aprender perpassa pela oralidade. A troca de saberes se dá, sobretudo, pela vivência e/ou encontro de gerações.

A percepção de mundo da comunidade é repassada a partir de saberes populares transmitidos pela oralidade e pelo convívio social. Para Tim Ingold (2010), a contribuição que cada geração dá à seguinte não é um suprimento acumulado de representações, mas uma educação da atenção. É preciso estar atento para aprender, pois o modo de aprender está atrelado à observação, ao olhar o outro fazer para assim aprender. Evidenciamos que as crianças da Vila de Mangueira observam atentamente os saberes difundidos através da oralidade pelos mais velhos, logo, os saberes vão se perpetuando no seu modo de agir e de pensar o mundo.

Dessa forma, os saberes tornam-se intrínsecos ao contexto vivenciado pelas crianças. Diante disso, o saber é construído na vida cotidiana, no ver e no fazer, e assim, vão se integrando ao cotidiano e se relacionando com a educação, com a realidade e com as particularidades de uma comunidade quilombola. Para Martinic (1994), a sabe- 
doria popular refere-se ao acervo de conhecimento produzido e acumulado historicamente pelos grupos sociais e permitem aos sujeitos relacionar suas experiências e objetivações, que encontram sentido nas práticas do grupo em que estão inseridos.

Desta feita, a educação pode ser encontrada nos diversos saberes populares. $\mathrm{O}$ processo de ensino-aprendizagem perpassa por diversos aspectos; entre os quais, destacamos a "educação da atenção", a qual é encontrada no cotidiano das crianças da Vila de Mangueira, conforme se observa nas passagens seguintes:

A gente tem que prestar a atenção para aprender, ficar olhando bem, não tirar o olho, porque senão queima a panela, aí estraga tudo e a gente fica sem comer, com fome (Jaburá,10 anos).

Meu pai que me ensinou a jogar bola. Ele mandou eu olhar ele jogando, eu fiquei só olhando bem, depois eu comecei a jogar, hoje eu sou bom de bola e ensino também, às vezes [risos] (Kelé,10 anos).

Eu vou para pesca e às vez pra fazenda. Meu pai leva pra ficar olhando ele fazer as coisas, eu olho bem pra aprender, e depois eu ajudo ele nas coisas do trabalho dele. E eu acho legal e divertido ir pra lá (Sarubé,10 anos).

Nas vozes das crianças, verifica-se um processo de ensino-aprendizagem que depende da atenção ao que acontece no entorno, e assim se aprende a cozinhar, a jogar bola e a pescar. A aprendizagem é baseada na atenção, na observação, no olhar o fazer do outro e posteriormente no exercício do fazer e do praticar, e esse processo se aplica tanto para se aprender as brincadeiras, quanto para atividades domésticas e atividades laborais comuns no contexto das comunidades quilombolas marajoaras.

Esse dado se aproxima da assertiva do antropólogo Tim Ingold (2010), em que o processo educacional envolve uma "educação da atenção", verificada no momento de "aprender a sintonizar o momento de sua atenção ao movimento da ação do outro 
que nos cerca". A educação proposta pela experiência considera o local de pertencimento e a vivência do sujeito, bem como a maneira como aprende e ensina, tendo na observação e na atenção os instrumentos de aprendizagem. Dessa forma, é necessária uma observação minuciosa e atenta para, assim, aprender o que o outro ensinar em seu fazer prático.

Considerando o brincar e as brincadeiras como espaço educativo, que propiciam o compartilhamento de saberes e a construção de processos e práticas educativas, Oliveira (2010, p. 87), quando se refere à interação, afirma que "as crianças, ao brincarem [...], interagem com seus pares construindo espaço-tempo de sociabilidade e aprendizagem por intermédio do qual se localizam e se posicionam no mundo social local”.

Tendo em vista o posicionamento social e local desses sujeitos, descrevemos alguns saberes protagonizados pelos intérpretes deste estudo. E com o intuito de dinamizar apresentamos no quadro abaixo, analisa-se o tipo de educação que se insere no contexto desses saberes. Nesses moldes, é importante mencionar que a circulação desses saberes se coaduna com as manifestações lúdicas das crianças quilombolas marajoaras residentes na Vila de Mangueira.

\section{Quadro dos Saberes e práticas educativas das crianças quilombolas marajoa-} ras

\begin{tabular}{|c|c|c|c|}
\hline O Saber & $\begin{array}{c}\text { Como o saber é } \\
\text { compartilhado }\end{array}$ & Processos e práticas educativas & Educação que o saber está associado \\
\hline \multirow{2}{*}{ SABERES LÚDICOS } & Oralidade & Brincar & \\
& Observação & Brincadeiras & Educação pela ludicidade e pela arte \\
& Orientação & Prática & Teatro (repetição das falas e representação dos \\
& Repetição & personagens) & \\
\hline
\end{tabular}

Cadernos de Pós-graduação, São Paulo, v. 17, n. 2, p. 99-119, jan./jun. 2018. 


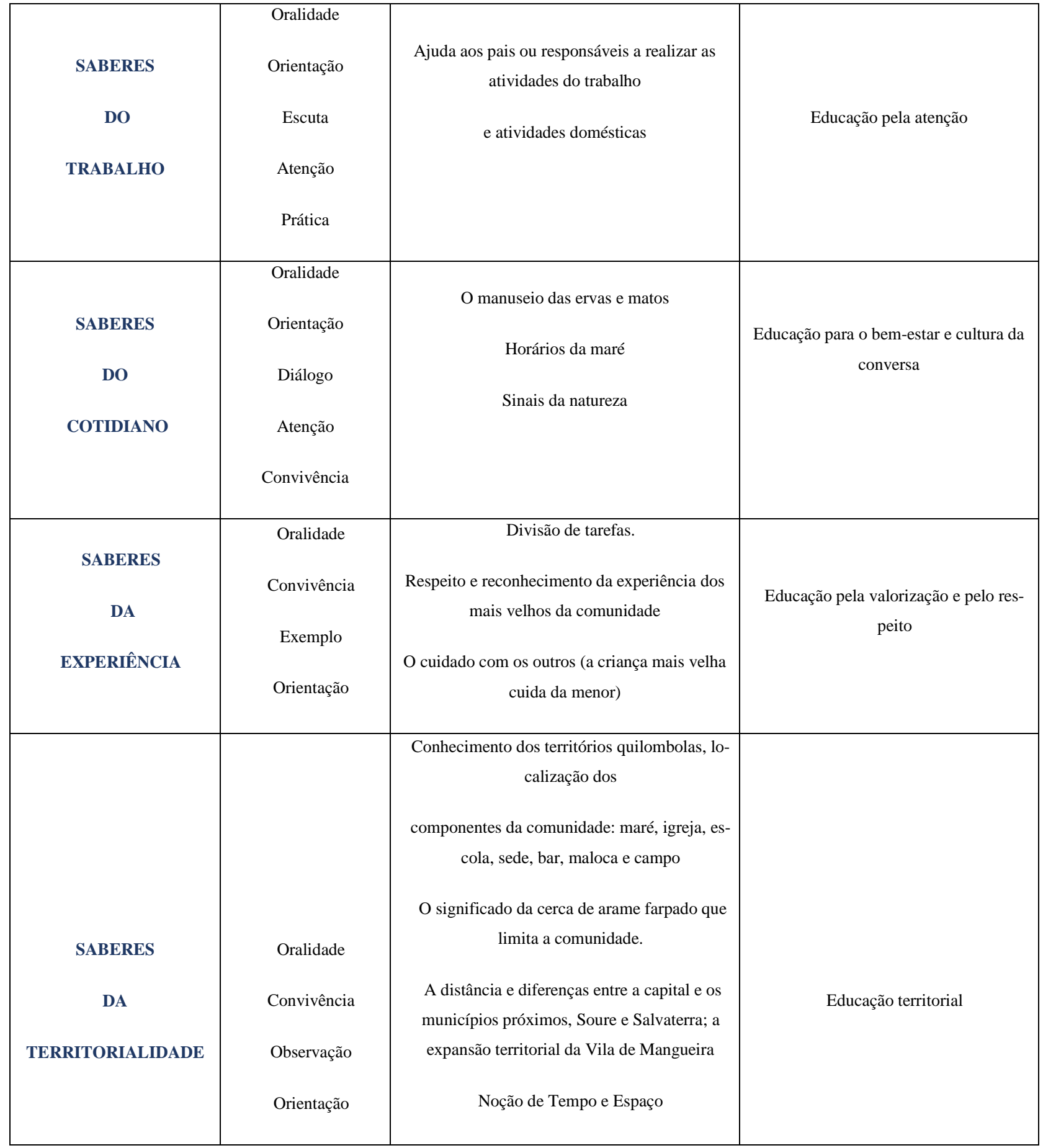




\begin{tabular}{|c|c|c|c|}
\hline SABERES & Oralidade & & \\
RELIGIOSIDADE & Observação & $\begin{array}{c}\text { Rezas; ladainhas; informações sobre práticas e } \\
\text { costumes religiosos }\end{array}$ & Educação religiosa \\
& Orientação & & \\
\hline
\end{tabular}

Fonte: Análises feitas nesta pesquisa pela autora

Conceber a educação na perspectiva dos saberes é legitimar os conhecimentos que se constroem nas práxis cotidianas. Assim, para Brandão (2002), a educação é cultura, pois o estudioso considera como prática educativa tudo o que o homem constrói, como seus saberes, significados e experiências de vida.

Nesse panorama, os saberes protagonizados pelas crianças nas suas vivências cotidianas compreendem práticas educativas que evidenciam uma educação que não se restringe apenas ao espaço da escola. Assim, a "educação aparece sempre que surgem formas sociais de condução e controle da aventura de ensinar - e - aprender” (BRANDÃO, 1995, p. 26).

Com base nesses ensinamentos vivenciados nas práxis cotidianas, identificamos cinco saberes: lúdicos, do trabalho, do cotidiano, da hierarquia, da territorialidade e da religiosidade, os quais se relacionam com diferentes tipos de educação, como Educação pela ludicidade e pela arte, "Educação pela atenção", Educação para o bem-estar e a cultura da conversa, Educação pela valorização e pelo respeito, Educação territorial e Educação religiosa. Nesses termos, reconhecer esses saberes provenientes das vivências das crianças quilombolas marajoaras é considerar um processo de ensino-aprendizagem que educa para além dos conteúdos cientificistas: educa para a vida.

Portanto, as manifestações lúdicas das crianças quilombolas da Vila de Mangueira se configuram como um espaço educativo pleno, onde o processo de ensinoaprendizagem se constitui em estar atento para aprender, e assim saber e fazer. Esses 
modos de ser, de aprender e de fazer foram revelados e protagonizados pelos intérpretes da pesquisa.

\section{Conclusão}

Ao longo desse trabalho percebemos que o conceito de educação acaba sendo ampliada, materializando o que escreve Brandão (2002), para quem “educação é cultura", e com isso reconhece a urgência de repensar e ressignificar os diferentes processos educativos. Assim, apresentamos neste estudo, saberes que concebem diferentes espaços e modos de aprendizagem, tais como os saberes lúdicos, saberes do trabalho, saberes do cotidiano, saberes da hierarquia, saberes da territorialidade e saberes da religiosidade.

Diante do exposto, entendemos claramente a necessidade de considerar a dinâmica de cada grupo social, respeitar suas especificidades e modos singulares de vida, pois estes, em grande parte, são ligados à cultura e às tradições desses grupos. Nesse sentido, notamos a necessidade e a urgência em desconstruir o paradigma hegemônico educacional das teorias ocidentais. Isto não significa que a escola não seja importante, sabemos que ela é relevante e de suma para os sujeitos, porém, não podemos mais limitar a educação a apenas esse espaço.

Tendo em vista que o educar extrapola os muros da escola e ocupa todas as dimensões das vivências das crianças quilombolas marajoaras. Nessa perspectiva, é fundamental visibilizar novas epistemologias, para assim compreender as identidades, as diferentes formas de viver, pensar, ensinar, aprender e educar, sobretudo, pensar em propostas de ensino que atendam as reais necessidades de sujeitos que vivem em território étnicos marcados pela luta pela terra e pela resistência em manter viva sua história, como é o caso das crianças da Vila de Mangueira. 


\section{Referências}

ALVES, Laura Maria Silva Araújo. A infância em construção: as fontes de investigação. In: ARAÚJO, Sonia Maria da Silva; ALVES, Laura Maria Silva Araújo; BERTOLO, Sônia de Jesus Nunes (Org.). Pesquisa e educação na Amarônia: reflexões epistemológicas e políticas. Belém: EDUEPA, 2014.

ANJOS, R. S. A. O Brasil africano: geografia e territorialidade. Brasília: CIGACESPE/UnB, 2010.

BRANDÃO, C. R. Educaşão como cultura. São Paulo: Mercado das Letras, 2002.

BROUGÈRE, Gilles. Brinquedo e cultura. São Paulo: Cortez, 2000.

CAILLOIS, Roger. Os jogos e os homens: a máscara e a vertigem. Lisboa: Ed. Cotovia, 1990.

COHN, Clarice. Antropologia da criança. 2. ed. Rio de Janeiro: Jorge Zahar Ed., 2005.

CORSARO, Willian A. Sociologia da infância. Porto Alegre: Artmed, 2011.

CRUZ, Silvia H. V. A criança fala: a escuta de crianças em pesquisas. São Paulo: Cortez, 2008.

GEERTZ, C. A interpretação das culturas. Rio de Janeiro: TLC, 2012.

HUIZINGA, Johan. Homo Ludens: o jogo como elemento da cultura. São Paulo: Perspectiva, 2012. 
INGOLD, Tim. Da transmissão de representações à educação da atenção. Educação, Porto Alegre, v. 33, n. 1, p. 6-25, jan./abr. 2010. Disponível em: < http://revistaseletronicas.pucrs.br/ojs/index.php/faced/article/view/677/4943>. Acesso em: 16 jan. 2018.

LE GOFF, J. História e memória. 2. ed. Campinas, SP: Ed. UNICAMP, 1992.

MALUNGU. Nova cartografia social da Amazônia: Quilombolas da ilha de Marajó Pará. Belém: Coordenação Estadual Associações de Remanescente de Quilombos do Estado Pará - MALUNGU, 2006.

MARTINIC, Sergio. Saber popular e Identidade. In: GADOT'TI, Moacyr; TORRES, Carlos Alberto (Org.). Educação popular: utopia latino-americana. São Paulo: Cortez; Edusp, 1994.

MEDAETS, Chantal. “Tu garantes?”: Reflexões sobre a infância e as práticas de transmissão de aprendizagem na região do baixo-tapajós. In: CONGRESSO LUSOAFRO-BRASILEIRO DE CIÊNCIAS SOCIAIS, DIVERSIDADES E (DES) IGUALDADES, 11, 2011, Salvador. Anais ... Salvador, BA: Universidade Federal da Bahia (UFBA). 1 CD-ROM.

OLIVEIRA, Assis da Costa. Crianças Indígenas: teoria, etnografia e direitos. In: BELTRÃO, Jane Felipe; MASTOP-LIMA (Org.). Diversidade, educação e direitos: Etnologia indígena. Belém: IMECI; EDUCIMAT, 2010.

QUINTEIRO, Jucirema. Infância e educação no Brasil: um campo de estudos em construção. In: FARIA, Ana L.G. de; DEMARTINI, Zelia de B. F; PRADO, Patrícia D. (Org.). Por uma cultura da infância: metodologias de pesquisas com crianças. Campinas, SP: Autores Associados, 2009.

SANTIN, S. Educação física: da alegria do lúdico à opressão do rendimento. 3. ed. ampl. Porto Alegre: EST Edições, 2002. 
SANTOS, B. S. A gramática do tempo: para uma nova cultura política. São Paulo: Cortez, 2007.

THOMPSON, J. B. Ideologia e cultura moderna: teoria social e crítica na era dos meios de comunicação de massa. Petrópolis, RJ: Vozes, 1995.

\section{Notas:}

${ }^{1}$ Utilizamos o termo quilombo-mãe para designar aquele que, segundo as memórias que me foram narradas por moradores de outras comunidades, foi o primeiro quilombo a ser formado em Salvaterra, sendo o refúgio inicial dos negros que fugiam da escravidão imposta nas fazendas de Soure.

${ }^{2}$ Fundação Cultural Palmares, entidade vinculada ao Ministério da Cultura (MinC).

3 Malungu é a palavra escolhida para nomear a Coordenação das Associações das Comunidades Remanescentes de Quilombos do Pará. Foi oficialmente fundada em março de 2004, como uma organização sem fins lucrativos e econômicos para representar as comunidades quilombolas do Pará

${ }^{4} \mathrm{Na}$ esfera federal, o INCRA - Instituto Nacional de Colonização e Reforma Agraria - é o órgão responsável por titular as terras de quilombo seguindo os procedimentos estabelecidos no Decreto Federal n. 4.887, de 2003, e na Instrução Normativa Incra n. 57, de 2009.

recebido em 26 ago. 2018 / aprovado em 19 out. 2018

\section{Para referenciar este texto:}

PERES, E. S.; CARVALHO, N. C. Os saberes e fazeres das crianças quilombolas MarajoaraSalvaterra-Pará. Cadernos de Pós-graduação, São Paulo, v. 17, n.2, p. 99-119, jul./dez. 2018. Disponível em: <https://doi.org/10.5585/cpg.v17n2.10315>. 